\title{
Temporal vs. spatial information as a reinforcer of observing
}

\author{
CRAIG A. BOWE and JAMES A. DINSMOOR \\ Indiana University, Bloomington, Indiana 47401
}

\begin{abstract}
Conditioned reinforcement interpretations of observing behavior predict that certain kinds of temporal information, but not spatial information, will reinforce observing. In a free operant observing experiment, pigeons pecked the left and right keys of a three-key panel to produce intermittent food deliveries. Pecks to the center key (observing responses) produced stimulus displays providing some birds with spatial information (which side key to peck) and other birds with temporal information (which component of a mixed variable-interval/extinction schedule was operating). Four of the six birds that could produce temporal information did so, whereas none of the six birds that could produce spatial information did so. The "information hypothesis" of observing apparently cannot explain this result.
\end{abstract}

The term "information" is widely employed among animal learning and behavior theorists in a commonsense, qualitative way to denote a variety of relations between the informing event and the event about which the information is given. Specifically, the informing event can allow the organism to "know about," "expect," or "behave appropriately with respect to" the where, when, how, what, and, perhaps, the why of another event. But, in practice, the term "information" has been used almost exclusively to denote something about the "when" of an event (i.e., temporal information), as, for example, in the early work by Egger and Miller (1962, 1963) or in the writings of Rescorla and his colleagues (Rescorla, 1972; Rescorla \& Wagner, 1972; but see Rescorla, 1978, for what seems to be a recent attempt to broaden his use of the term). In Rescorla's work, a stimulus appeared in an organism's environment "predicting" an event that was important for the organism (e.g., food or shock). Prediction was possible because the probability that the event would occur (or not occur, in inhibitory conditioning) was greater during or soon after the stimulus than it was during or soon after any other stimulus.

The early restriction of the term "information" to temporal relations between events was nearly inevitable because theory and research in conditioning had emphasized the variable of temporal contiguity. Nevertheless, "information" now is usually meant to include relations other than temporal ones, thus providing the theorist with a useful integrating concept. Unfortunately, the meaning of "information" has been overextended by some theorists to include not only a discriminative/ informative function that relates informing events to aspects of other events, but also a reinforcing function. Egger and Miller $(1962,1963)$ discussed the reinforcing function and the discriminative/informative function of the stimuli in their experiments and argued that the latter was necessary for the former. Their argument was taken a step further by some researchers interested in the acquisition and maintenance of "observing responses" who claimed that information was sufficient to reinforce observing responses (see Fantino, 1977, or Dinsmoor, Note 1, for discussion of the differences between the "information hypothesis" of observing and several versions of conditioned reinforcement explanations for observing).

The present experiment employed pigeons in an observing paradigm and sought to determine whether spatial information would be reinforcing if it indicated which of two keys must be pecked to produce food. Previous experiments employing pigeons have shown that the temporal information provided when the observing response produces an $\mathrm{S}+$ is necessary to support the observing response, whereas production of an S- suppresses pigeons' observing responses (e.g., Dinsmoor, Browne, \& Lawrence, 1972; Mulvaney, Dinsmoor, Jwaideh, \& Hughes, 1974; but see Lieberman, 1972, or Schrier, Thompson, \& Spector, 1980, for their quite different conclusions when monkeys are used as the subjects). Both the "information hypothesis" and conditioned reinforcement hypotheses of observing predict that certain kinds of temporal information (i.e., when the S+ occurs) will support observing. The "information hypothesis" of observing, however, seems to be based on the idea that observing responses may be acquired and maintained when they provide the organism with information of any sort about primary reinforcement. And although no proponent of the "information hypothesis" of observing has made an explicit prediction regarding the support of observing responses by spatial information, the broad way in which this hypothesis is usually stated implies that spatial information of the present sort should support observing. On the other hand, the concept of conditioned reinforcement is based solely on temporal relations between stimuli and primary reinforcers (or sometimes on the 
relations among stimuli, responses, and primary reinforcers). Thus, if observing responses are acquired and maintained due to conditioned reinforcement, the present kind of spatial information is neither necessary nor sufficient for observing.

\section{METHOD}

\section{Subjects}

Twelve White Carneaux pigeons were deprived of food until they reached about $75 \%$ of their free-feeding weights. They were maintained at those weights with supplementary feedings after experimental sessions. Water and grit were freely available in each bird's home cage. All the birds had been trained in standard and discriminated autoshaping experiments to peck a key, but they had never been trained to peck a key to change the color of another key.

Three squads of four birds were used; each squad finished the experiment before the next squad began. Within each squad, two birds were assigned to the spatial information condition and the other two to the temporal information condition.

\section{Apparatus}

A standard operant conditioning chamber $30 \mathrm{~cm}$ wide, $35 \mathrm{~cm}$ across the front panel, and $35 \mathrm{~cm}$ high was used for the experiment. Three plastic keys were aligned horizontally behind circular openings in the front panel of the chamber such that each key was $10 \mathrm{~cm}$ from the ceiling and each side key was $11.5 \mathrm{~cm}$ from the nearest wall and $6.0 \mathrm{~cm}$ from the center key. (All measurements were made with respect to the centers of the keys.) A Type 757 bulb was placed in a metal housing located just above the center key. The bulb was supplied with $28 \mathrm{~V} \mathrm{dc}$ throughout the experimental sessions to provide general illumination of the chamber. A rectangular opening located beneath the center key allowed access to a food hopper that delivered mixed grain during the $3-\mathrm{sec}$ periods of reinforcement. Another Type 757 bulb, located inside the opening, was supplied with $28 \mathrm{~V}$ dc whenever the hopper was operated. A ventilating fan provided a constant low-intensity noise that masked extraneous sounds during the sessions.

Various colors were projected on the keys by Industrial Electronic Engineers cells mounted behind the front panel. Each cell contained 12 Type 44 bulbs. When $6.3 \mathrm{~V}$ ac was supplied to a specified group of four bulbs, one of the three colors, blue (Roscolene Filter 854, 450-500 nm), orange (Kodak-Wratten Filter 22, $599 \mathrm{~nm}$ ), or green (Kodak-Wratten Filter $56,555.5 \mathrm{~nm}$ ), appeared on a key.

Experimental events were controlled and recorded by Massey-Dickinson programming and data gathering equipment located outside the room that contained the pigeon chamber.

\section{Procedure}

Pretraining. All birds were pretrained in six successive sessions to peck the three keys for 3-sec food deliveries. During pretraining sessions, only one key could be pecked because the other two were covered with tape. The birds were first shaped to peck the center key and were allowed 30 reinforcers on a continuous reinforcement schedule. On the next three sessions, they were shifted to a variable-interval (VI) 15 -sec schedule, then to a VI 30-sec schedule, and finally, to a VI 60-sec schedule. They pecked the center key for 60 reinforcers on each of these schedules. On the final two sessions of pretraining, the birds received 60 reinforcers on the VI 60 -sec schedule for pecks to the left key and then for pecks to the right key.

Spatial vs. temporal information. All keys were uncovered to begin this part of the experiment. The three basic features of spatial vs. temporal information were: (1) the primary reinforcement contingencies for pecks to the side keys, (2) the observing response as defined by pecks to the center key, and (3) the kinds of information produced by the observing response. Two conditions specified where and when a pigeon should peck to produce food. A dual-state programming device that switched states according to a variable-time (VT) 60 -sec schedule determined whether the right or the left key was "correct" during any given part of a 90-min session. A correct key was one for which reinforcers were set up and "held" as described below. Pecks to a correct key could sometimes yield a reinforcer, but pecks to an incorrect key (i.e., the other side key) could not. Whenever one side key was correct, the other was incorrect, and each side key was correct for variable periods totaling half a session. A second dual-state programming device that switched states according to a VT $60-\mathrm{sec}$ schedule independent of the first determined whether a VI 60-sec component or an extinction component from a mixed schedule was operating during any given part of a session. When the VI 60-sec component was operating, reinforcers were set up for the correct key on the average of one every $60 \mathrm{sec}$ and were held until a peck to the correct key delivered the reinforcer. However, pecks to the correct key would yield a reinforcer only during the operation of the VI 60-sec component. Pecks were never reinforced during the extinction component, even though the pigeon pecked a correct key for which a reinforcer was being held. The two components of the mixed schedule alternated throughout a session such that each operated for variable periods totaling half a session. To summarize, the conditions necessary for producing food were that a pigeon peck the correct key during the VI 60-sec component when that key held a reinforcer.

If a pigeon did not peck the center key (i.e., did not observe), all three keys remained blue. However, according to a VI 30-sec schedule, pecks to the center key produced 30 -sec stimulus displays such that the center key became dark and both side keys either became orange or became green. The color that appeared depended on which of the four contingencies of primary reinforcement (left key correct, VI 60-sec; left key correct, extinction; right key correct, VI 60-sec; right key correct, extinction) was in effect at the moment, as well as on the information condition assigned to the bird. After a stimulus display, all three keys became blue again. The VI 30 -sec schedule for pecks to the center key stopped operating during the stimulus displays. Also, each peck to the center key began a 2-sec period during which pecks to the side keys could not produce food. Thus, pecks to the center key were observing responses that could only begin stimulus displays and were never followed within $2 \mathrm{sec}$ by a primary reinforcer.

For a given bird, stimulus displays provided only one of the two possible kinds of information about the contingencies of primary reinforcement: spatial information or temporal information. Stimulus displays for the spatial information condition were such that whenever the left key was correct, the side keys were green and whenever the right key was correct, the side keys were orange. When the position of the correct key changed during a stimulus display, the colors changed accordingly. Stimulus displays for the temporal information condition were such that whenever the VI 60-sec component was operating, the side keys were orange and whenever the extinction component was operating, the side keys were green. When the component that was operating changed during a stimulus display, the colors changed accordingly.

Figure 1 summarizes the essential features of the procedure for the 15 sessions of spatial vs. temporal information.

\section{RESULTS}

The crucial question was whether the two types of information would both support center-key pecking (observing). Because primary reinforcement was no 


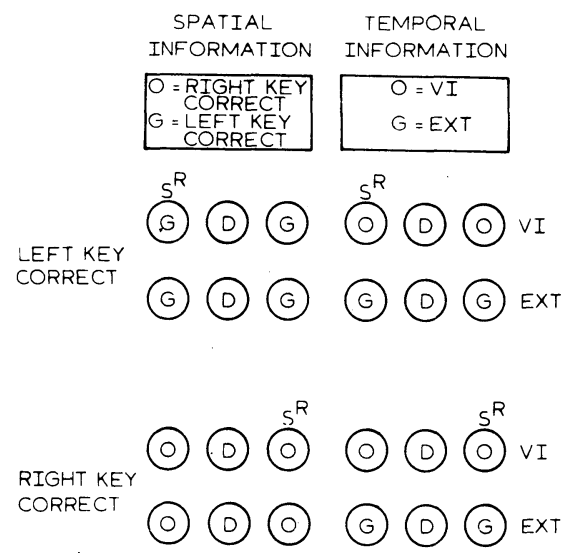

Figure 1. Schematic diagram of how the stimulus displays for the spatial information condition and for the temporal information condition appear on the three keys under each of the four contingencies of primary reinforcement. $\mathrm{O}=$ orange, $\mathrm{G}=$ green, $D=$ dark; $S^{R}=$ pecks to this key sometimes produce food.

longer available for center-key pecks during the 15 sessions of spatial vs. temporal information, a decline in the number of such pecks was to be expected, limited only by the extent to which the pecking was maintained by the reinforcing effect of each kind of information. The top two panels of Figure 2 show the mean number of center-key pecks made by birds receiving spatial information and birds receiving temporal information. An analysis of variance was conducted for the two kinds of information and the three session blocks. The main effect for the kind of information did not reach an acceptable level of significance $[\mathrm{F}(1,10)=3.29, \mathrm{p}>.05]$, but the main effect for session blocks did reach such a level $[F(2,20)=22.99, p<.01]$, and, more important, so did the interaction between the kind of information and session blocks $[F(2,20)=3.87, p<.05]$. This analysis supports the impression gained from inspection of the top panels of Figure 2 that: (1) in the first session block, there was little difference between the two information conditions in the rate of pecking on the center key, (2) for both information conditions, there was a decrease in the number of pecks to the center key from the first to the third session block, and (3) the amount of decrease in the number of pecks to the center key from the first to the third session block was less for the temporal information condition than for the spatial information condition.

Comparisons of each bird's observing behavior with its group's average may be made by inspecting the lower panels of Figure 2. All birds from the spatial information condition exhibited the same pattern that was found for the group, that is, failure to maintain pecks to the center key across session blocks. The individual patterns of observing by the birds from the temporal information condition fell into two distinct categories: failure to maintain pecks to the center key (6322 and 5845) and maintenance of center-key pecking $(4199,3016,5600$, and 3923).
In addition to observing, an important aspect of the present experiment was the ability of the birds to use their respective kinds of information to direct side-key pecking. All birds pecked the side keys substantially more than they pecked the center key. And, although some birds developed preferences for pecking a particular side key, these preferences were not so exclusive that the birds missed scheduled reinforcers by failing to regularly peck the nonpreferred key. Two discrimination ratios were calculated for each bird that over the last five sessions of the experiment pecked the side keys at least 20 times during stimulus displays. This 20-peck criterion restricts the following analysis of discriminative performance to five birds from each information condition. A spatial discrimination ratio (SDR) was calculated for the last five sessions by dividing the number of pecks to the correct key during stimulus displays by the total number of pecks to the side keys during stimulus displays. A temporal discrimination ratio (TDR) was calculated for the last five sessions by dividing the number of pecks to the side keys when the VI 60-sec component was operating during stimulus displays by the total number of pecks to the side keys during stimulus displays. An SDR of 1.00 would indicate that during stimulus displays, a bird always pecked the correct key, whereas an SDR of .50 would indicate that

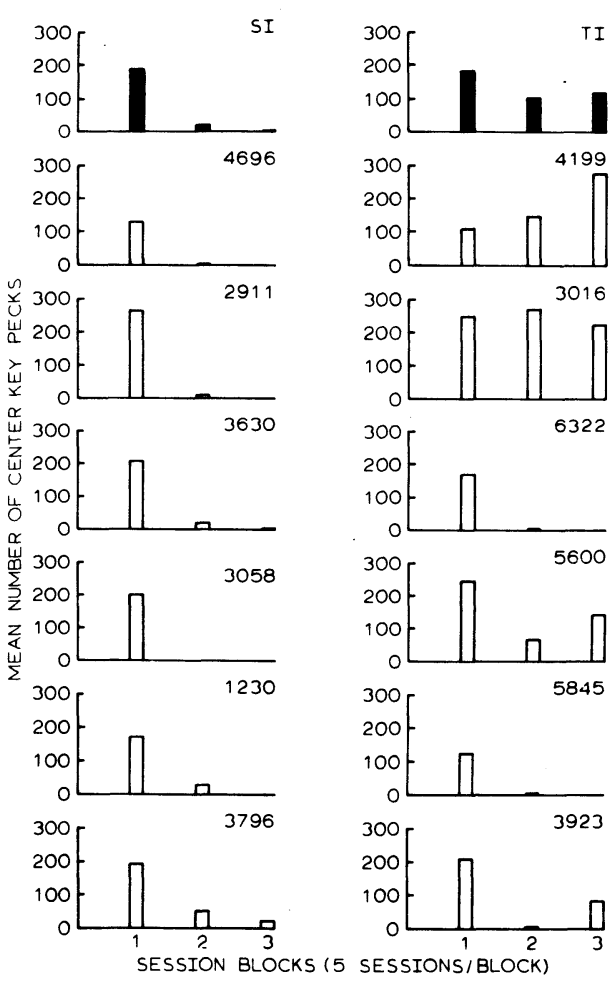

Figure 2. Group and individual observing plotted as the mean number of center-key pecks for each of the three session blocks (5 sessions/block) in spatial vs. temporal information. The top two panels depict the group means and the remaining panels the results for the individual birds. SI = spatial information; $\mathrm{TI}=$ temporal information. 
during stimulus displays, a bird was unable to discriminate which side key was correct. Similarly, a TDR of 1.00 would indicate that during stimulus displays, a bird pecked the side keys only when the VI 60-sec component was operating, whereas a TDR of .50 would indicate that during stimulus displays, a bird was unable to discriminate when the VI 60-sec component was operating. Note that although an SDR was calculated for the birds from the temporal information condition and a TDR was calculated for the birds from the spatial information condition, these ratios served only as a check on the possibility that stimuli other than the key colors were used to make the appropriate discriminations. In the absence of such stimuli, both of these ratios should be .50. Birds from the temporal information condition were able to discriminate when the VI 60-sec component was operating, but they were unable to discriminate which side key was correct (group mean $\mathrm{TDR}=.95, \mathrm{SDR}=.48$ ). The group mean discrimination ratios of the birds from the spatial information condition were in the expected direction; that is, ability to discriminate which key was correct and inability to discriminate when the VI 60-sec component was operating (group mean SDR $=.69, \mathrm{TDR}=.53$ ). Two of the birds from this condition, however, failed to discriminate which key was correct.

\section{DISCUSSION}

Temporal information supports observing by pigeons if it distinguishes periods during which keypecks yield a high reinforcement density from periods during which keypecks yield a low reinforcement density. Spatial information, however, does not support observing by pigeons if it distinguishes which of two keys is to be pecked to produce reinforcement. This fact is damaging to the "information hypothesis" of observing, but it is quite consistent with a conditioned reinforcement viewpoint.

Most of the birds from the temporal information condition regularly pecked both side keys during orange stimulus displays. On these occasions, they had produced a stimulus correlated with a higher reinforcement density (an average of one reinforcer per $60 \mathrm{sec}$ ) than either of the other two stimuli that could appear on the keys, blue (an average of one reinforcer per $120 \mathrm{sec}$ ) or green (zero reinforcers). According to Dinsmoor's conditioned reinforcement analysis of observing, which relies on a correlation between stimuli and reinforcement densities (Browne \& Dinsmoor, 1974), the temporal information condition should cause the acquisition and maintenance of observing, and so the maintenance of center-key pecking, although not reinforced with food, was expected. Four of the six birds from the temporal information condition behaved in accordance with this expectation, but two of the birds failed to observe. This failure was probably due to their low rates of pecking the side keys during orange stimulus displays (average rates of side-key pecks during orange stimulus displays over the 15 sessions of spatial vs. temporal information for 5845 and 6322 were .98 and $6.90 \mathrm{pecks} / \mathrm{min}$, respectively) that, in turn, resulted in very few reinforcers during stimulus displays (totals of four and six reinforcers, respectively). Apparently, these birds did not make adequate contact with the experimental contingencies.

The reinforcement density analysis can also explain the failure of all birds from the spatial information condition to observe. Whenever the birds from this condition produced either orange or green stimulus displays via their observing responses and then pecked the correct key, they could obtain reinforcers only at the same frequency (i.e., an average of one reinforcer per $120 \mathrm{sec}$ ) as that at which they could obtain reinforcers in the presence of the blue keys that prevailed when no observing responses were made. The reinforcement density analysis predicts no observing if, as was true of the spatial information condition, there is no stimulus associated with a reinforcement density higher than that in the presence of stimulus conditions prevailing when observing responses are not made.

The failure by two of the birds from the spatial information condition to develop good spatial discriminations (i.e., large SDRs) forces some qualification of our conclusions about observing for spatial information. This failure to discriminate could mean that, at least for those two birds, even though spatial information was available operationally, it was not functionally available, so that their failure to observe under this condition was trivial. Whereas this possibility existed in our present design, we intend future tests that will not be susceptible to this argument. Nevertheless, three of the birds from the spatial information condition discriminated which key was correct and yet failed to observe. Therefore, the present results generally support a conditioned reinforcement analysis of observing and threaten the generality of the "information hypothesis."

\section{REFERENCE NOTE}

1. Dinsmoor, J. A. The reinforcement of observing. Unpublished manuscript, 1980.

\section{REFERENCES}

Browne, M. P., \& Dinsmoor, J. A. Wyckoff's observing response: Pigeons learn to observe stimuli for free food but not stimuli for extinction. Learning and Motivation, 1974, 5, 165-173.

Dinsmoor, J. A., Browne, M. P., \& Lawrence, C. E. A test of the negative discriminative stimulus as a reinforcer of observing. Journal of the Experimental Analysis of Behavior, 1972, 18, 79-85,

EgGer, M. D., \& Miller, N. E. Secondary reinforcement in rats as a function of information value and reliability of the stimulus. Journal of Experimental Psychology, 1962, 64, 97-104.

EgGer, M. D., \& Miller, N. E. When is a reward reinforcing? An experimental study of the information hypothesis. Journal of Comparative and Physiological Psychology, 1963, 56, 132-137.

Fantino, E. Conditioned reinforcement: Choice and information. In W. K. Honig \& J. E. R. Staddon (Eds.), Handbook of operant behavior. Englewood Cliffs, N.J: Prentice-Hall, 1977.

Lie Berman, D. A. Secondary reinforcement and information as determinants of observing behavior in monkeys (Macaca mulatta). Learning and Motivation, 1972, 3, 341-358.

Mulvaney, D. E., Dinsmoor, J. A., JWaideh, A. R., \& Hughes, L. H. Punishment of observing by the negative discriminative stimulus. Journal of the Experimental Analysis of Behavior, 1974, 21, 37-44.

Rescorla, R. A. Informational variables in Pavlovian conditioning. In G. H. Bower (Ed.), The psychology of learning and motivation (Vol. 6). New York: Academic Press, 1972.

RESCORLA, R. A. Some implications of a cognitive perspective on Pavlovian conditioning. In S. H. Hulse, H. Fowler, \& W. K. Honig (Eds.), Cognitive processes in animal behavior. Hillsdale, N.J: Erlbaum, 1978.

Rescorla, R. A., \& Wagner, A. R. A theory of Pavlovian conditioning: Variations in the effectiveness of reinforcement and nonreinforcement. In A. H. Black \& W. F. Prokasy (Eds.), Classical conditioning II: Current research and theory. New York: Appleton-Century-Crofts, 1972.

Schrier, A. M., Thompson, C. R., \& Spector, N. R. Observing behavior in monkeys (Macaca arcotoides): Support for the information hypothesis. Learning and Motivation, 1980, 11, 355-365.

(Received for publication December 17, 1980.) 